\title{
Therapeutic itinerary of severe malaria in adults admitted to a teaching hospital in Dakar, Senegal
}

\author{
Sylvie A Diop ${ }^{1,2}$, Cossi Angelo Attinsounon ${ }^{1}$, Louise Fortes-Déguénonvo ${ }^{1}$, Viviane Marie Pierre Cisse \\ Diallo $^{1}$, Moussa Seydi ${ }^{1}$ \\ ${ }^{1}$ Clinique des Maladies Infectieuses, Centre Hospitalier Universitaire de Fann, Université Cheikh Anta Diop de \\ Dakar, Sénégal \\ ${ }^{2}$ UFR Santé -Université de Thiès, Sénégal
}

\begin{abstract}
Introduction: Despite prevention efforts, malaria remains a public health problem. Methodology: This was a prospective study conducted between October and December 2010 that aimed to describe the therapeutic route of adults presenting with severe malaria prior to being admitted to Fann Teaching Hospital in Dakar, Senegal.

Results: A total of 90 patients were included. The majority of them had consulted a public or private health care facility (92\%) prior to admission. First consultation occurred on average two days after the onset of the disease. Self-medication (67.4\%) and traditional medicine $(26.1 \%)$ were the main causes of delaying care.

Conclusions: Early care and adequate management are needed to reduce malaria mortality.
\end{abstract}

Key words: malaria; adults; itinerary; Senegal; sub-Saharan Africa.

J Infect Dev Ctries 2014; 8(10):1353-1355. doi:10.3855/jidc.4957

(Received 05 March 2014 - Accepted 28 May 2014)

Copyright (C) 2014 Diop et al. This is an open-access article distributed under the Creative Commons Attribution License, which permits unrestricted use, distribution, and reproduction in any medium, provided the original work is properly cited.

\section{Introduction}

In Senegal, malaria control strategies have been strengthened by the extension in 2007 of rapid diagnostic tests (RDTs) for malaria and the use of combination therapy with artemisinin (CTA). As a consequence, in some areas a "pre-elimination" of malaria has been achieved. Despite these significant advances, malaria still causes high mortality and remains the most common reason for emergency admission in Fann Teaching Hospital, Dakar, Senegal. According to previous studies, delays in diagnosis and default of care were the main factors that contributed to the development of severe malaria [1-3]. This may have changed with prevention efforts. The purpose of this study was to trace the therapeutic route of severe malaria cases before their admission to the infectious diseases clinic in Fann Teaching Hospital, in order to make recommendations for better management of malaria.

\section{Methodology}

The study was conducted between 1 October and 31 December 2010. All severe malaria cases among hospitalized patients, based on World Health
Organization (WHO) criteria, were included [4]. Those patients who had not been administered an RDT or a thick blood film or any other examination confirming the diagnosis of malaria were not included. Data were collected through examination of patients and/or their relatives and after consultation of transfer sheets and previous requirements. The data consisted of the following variables: socio-demographic data, therapeutic itinerary before admission (consultations, hospitalizations, length of stay, type of prior therapies, their dosage and mode of administration, use of African traditional medicine), delay between first consultation period and hospitalization, and reasons for default of care. Data were analyzed using Epi Info version 3.5.1 (CDC, Atlanta, USA).

\section{Results}

A total of 106 cases were included; 90 (85\%) were severe forms. The mean age was $31.26 \pm 16.77$ years. A male predominance was noted $(65.6 \%)$ with a sex ratio $(\mathrm{M} / \mathrm{F})$ of 1.90 . The majority of patients came from Dakar and its suburbs. Most of the patients $(73.3 \%)$ did not use mosquito nets mainly because of a lack of money (53.6\%), lack of space in the room 
(29.8\%), and feelings of suffocation (8\%). The sociodemographic characteristics of the study population are summarized in Table 1.

Seventy-one patients did not present to a medical professional immediately after the onset of symptoms. They used first-line self-medication $(67.4 \%)$ or had consulted a traditional healer $(26.1 \%)$. The patients had consulted, on average, after a period of two days, one (50 patients), two (19 patients), or three health (2 patients) facilities before admission to the clinic where they received a CTA prescription in $40 \%$ of cases and a quinine or artemether injection. This treatment was administrated as prescribed in $66.2 \%$ of patients. Persistence or occurrences of vomiting were the main causes of non-compliance with this treatment. More than $2 / 5$ of patients $(44.4 \%)$ had even been hospitalized prior to admission to the clinic, and the average length of stay was $2.02 \pm 1.36$ days.

The rapid diagnostic tests for malaria were performed in $40 \%$ of patients and thick blood films in $7.8 \%$ of patients. No diagnostic testing was performed in $31 \%$ of patients.

Because of worsening symptoms, patients were transferred to our clinic. In most cases, neurological symptoms were the determining motive. Other signs, such as respiratory distress, coma, jaundice, severe anaemia, were also noted (Figure 1). Overall mortality was $33.3 \%$ in this study. According to previous studies, severe malaria in adults remains a reality [1$3,5,6]$. This segment of the population therefore requires special attention.

\section{Discussion}

Our results showed the non-observance of the main preventive measure in the general population. In a previous study, Ndiaye et al. [7] noted that only $16 \%$ of the population of Dakar slept under a mosquito net. Use of self-medication and visiting a traditional doctor
Figure 1. Main severity signs of malaria reported in patients being admitted to the infectious disease clinic in Fann Teaching Hospital

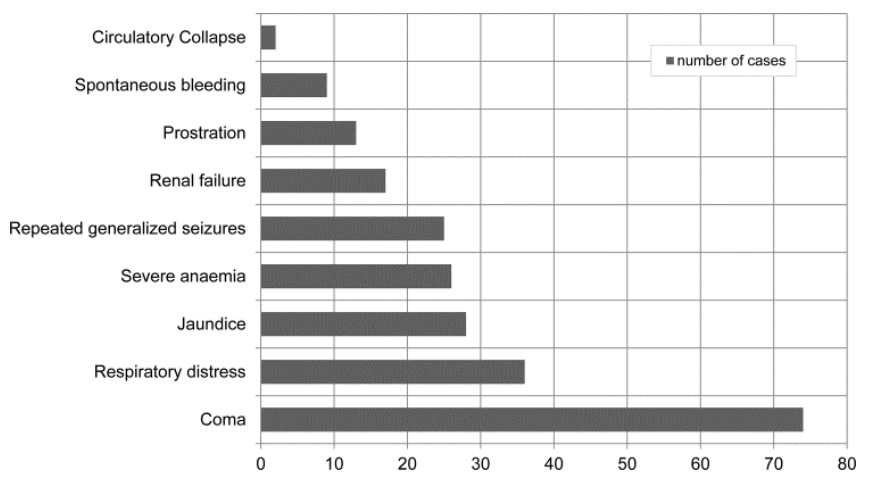

were the main causes of delay in care. These data were comparable to those obtained by Severov in Guinea [5]. Other factors were identified in others studies; these included availability and geographical accessibility of health services, social representations, and financial difficulties [2,8]. Although it has improved, malaria diagnostic confirmation is still low; however, studies have shown the sensitivity and specificity of RDTs that have become an essential tool. The low use of RDTs in public health facilities indicates a lack of enforcement of national guidelines, as demonstrated in a study in Burkina Faso [8], and should be evaluated. In addition, a study in Senegal showed that the use of RDTs involved a change in behavior that caregivers and recipients were not always willing to comply with [9].

\section{Conclusions}

Malaria still causes a high case fatality in the teaching hospital. Several factors appear to be associated with the occurrence of severe malaria; these include delayed care due to self-medication practices and inadequate treatment. In addition, treatment on clinical suspicion is still a striking reality.

Table 1. Socio-demographic characteristics of the study population

\begin{tabular}{|c|c|c|c|}
\hline \multicolumn{2}{|c|}{ Characteristics } & \multirow{2}{*}{$\begin{array}{c}\text { Frequency } \\
31\end{array}$} & \multirow{2}{*}{$\frac{\text { Percentage }}{35.4}$} \\
\hline & Female & & \\
\hline Sex & Male & 59 & 65.6 \\
\hline \multirow{3}{*}{ Age } & $0-20$ & 30 & 33.3 \\
\hline & $41-60$ & 12 & 13.3 \\
\hline & $61-80$ & 7 & 7.7 \\
\hline \multirow{3}{*}{ Geographical origin } & Dakar & 40 & 44.4 \\
\hline & Dakar suburb & 35 & 38.9 \\
\hline & Other regions & 15 & 16.7 \\
\hline
\end{tabular}


Communication strategies and information on adherence to preventive measures of malaria should be strengthened. Systematic studies are needed to identify the reasons for insufficient patient management in the health facilities.

\section{References}

1. Diop SA, Ndour CT, Dia NM, Manga NM, Fortes L, Lakhe NA, Niang K, Seydi M, Soumare M, Diop BM, Sow PS (2010) Aspects actuels du paludisme grave de l'adulte. Med Afr Nre 4: 193-197.

2. Eholié SP, Ehui E, Adou-Bryn K, Kouamé KE, Tanon A, Kakou A, Bissagnené E, Kadio A (2004) Paludisme grave de l'adulte autochtone à Abidjan, Côte d'Ivoire. Bull Soc Pathol Exot 97: 340-344.

3. Soumaré M, Seydi M, Diop SA, Diop BM, Sow PS (2008) Neuropaludisme de l'adulte à la clinique des maladies infectieuses du CHU de Fann de Dakar, Sénégal. Bull Soc Pathol Exot 101: 20-21.

4. World Health Organization (2000) Severe and complicated malaria. Trans R Soc Trop Med Hyg 94 Suppl 1:1-90.

5. Severov MT, Comolet T, Magassouba N, Marly B, Diallo A, Sank A (2000) Epidémiologie du paludisme grave chez l'adulte à Conakry (Guinée): Implications pour la stratégie et le contrôle. Med Afr Noire 47: 65-71.

6. Wade KA, Sene BE, Niang EM, Diallo A, Diatta B (2012) Epidemiology and prognostic value of organ failure during severe malaria in the Principal Military Teaching Hospital of Dakar, Senegal. Med Sante Trop 22: 422-424.

7. Ndiaye S, Ayad M (2009) Enquête Nationale sur le Paludisme au Sénégal 2008-2009. Calverton, Maryland, USA: Centre de Recherche pour le Développement Humain (Sénégal) et ICF Macro.

8. Yaméogo TM, Kyelem CG, Ouédraogo SM, Diallo OJ, Moyenga L, Poda GEA, Guiguemdé TR (2011) Diagnostic et prise en charge du paludisme grave chez l'adulte: observance des directives nationales au Burkina Faso. Bull Soc Path Exot 104: 284-287.

9. Faye SL (2012) Améliorer la prise en charge du paludisme par les tests de diagnostic rapide (TDR) : appropriation par les prestataires et bénéficiaires de soins au Sénégal Bull Soc Path Exot 105: 237-244.

\section{Corresponding author}

Sylvie Audrey Diop

Service des Maladies infectieuses,

Centre National Hospitalier Universitaire de Fann

BP 5035 Dakar Fann, Senegal

Phone:+ 221776459050

Email: sylviediop@gmail.com

Conflict of interests: No conflict of interests is declared. 